\title{
2006-2635: TECHNOPOLIS CREATION - A SURVEY OF BEST PRACTICES FROM AROUND THE WORLD
}

\section{Carmo D'Cruz, Florida Tech}

Dr. Carmo A. D'Cruz is Associate Professor in the Engineering Systems Department at Florida Tech. A twenty-year veteran of the semiconductor industry, Dr. D'Cruz has studied and taught at Engineering and Business schools. His experience ranges from R\&D and engineering to manufacturing, operations, marketing and Business Development. His research areas include Technopolis Creation and Engineering Entrepreneurship. He has developed pioneering courses in Systems Engineering Entrepreneurship, Technical Marketing, High Tech Product Strategy and Technology Commercialization Strategies.

\section{Clifford Bragdon, Florida Tech}

Dr. Bragdon is a Distinguished Research Professor, and Associate Provost and Dean at Florida Institute of Technology. He has authored five books and over 100 articles as well as either a PI or Co-PI on over $\$ 50,000,000$ worth of university based research. Previous to FIT he was Associate Vice-President, Associate Dean and Professor at Georgia Institute of Technology. Previously he was Vice President and Dean of the School of Aviation and Transportation at Dowling College and the Director of the National Aviation and Transportation Center in New York. His Ph.D. is in the field of City Planning from the University of Pennsylvania.

\section{Dennis Kulonda, Florida Tech}

Dr. Dennis J. Kulonda is a scholar/entrepreneur with substantial academic and industry experience. He served as Director of the Engineering Management Program at the University of Central Florida; Dean, College of Business at Alfred University, New York; and Director of the Center for Professional Development at James Madison University. He has had industry experience as Managing Partner of Operations Associates; manager of Education Consulting at Broadway \& Seymour; and Industry Consultant at Management Science America. Dr. Kulonda has co-authored more than forty refereed journal articles, refereed proceedings and books. He has a BSIE from Kettering University, an MSIE from Cornell University and a Ph.D. from N.C.S.U.

\section{Kenneth Ports, QTS, Inc.}

Dr. Kenneth A. Ports is currently Senior Scientist at QTS, Inc. in Cocoa Beach, Florida. Until recently, Dr. Ports was a Professor in the Electrical and Computer Engineering Department and Associate Dean in the College of Engineering at Florida Tech. Prior to Florida Tech, Dr. Ports spent 25 years in the microelectronics industry in technical, management, staff and internal consulting roles. He led several corporate programs, including project management, product to market, technology roadmapping, and strategic planning. He was corporate director of University Relations, and his duties included overseeing the research pipeline. He has over 40 publications and papers, numerous company-private handbooks and documents, and 11 patents. He has a B.S. in Physics from Penn State and an M.S. and Ph.D. in Physics from Purdue University. 


\title{
Technopolis Creation \\ - A Survey of Best Practices from Around the World \\ Carmo D'Cruz, Clifford Bragdon, Dennis Kulonda \\ Florida Tech, Melbourne, Florida
}

\author{
Ken Ports \\ QTSI, Inc \\ Cocoa Beach, Florida
}

\begin{abstract}
Technopolis communities are sprouting up all over the world and are creating a profound impact on global economic landscapes. Today's global economy can be characterized by increasing globalization, heightened interdependency and the emergence of a new paradigm of regional, institutional and technological clusters, which facilitate innovation and its commercialization, called the "Technopolis Phenomenon".

This paper reviews research done on creation of Technopolis communities and highlights exemplary best practices from Technopolis communities around the world such as Silicon Valley, Boston, Austin, Ireland, Bangalore, Taiwan, Sophia-Antipolis, and others. The role of academia-industry-government collaboration in creation of Technopolis communities is discussed in detail. This involves sustained, collaborative efforts by academics, industry representatives, Entrepreneur Support Organizations (ESOs), Economic Development Organizations (EDOs), engineers, entrepreneurs, investors, and other practitioners to develop initiatives, plans, methodologies, infrastructure, and action items for Technopolis creation.

The authors' experiences in attempting to create a Technopolis community on the Space Coast of Central Florida add insights for program implementation and effectiveness. Engineering education programming linking academic / continuing education programs with experiential entrepreneurship and community outreach activities is emphasized. Critical Success Factors for Technopolis creation are identified.
\end{abstract}

\section{Introduction}

Today's global economy can be characterized by increasing globalization, heightened interdependency and the emergence of a new paradigm of regional, institutional and technological clusters, which facilitate innovation and its commercialization, called the "Technopolis Phenomenon".

A Technopolis (plural Technopoleis) is a region trying to build and maintain a healthy, technology-driven economy. ${ }^{1}$

Dr. Fred Phillips (ex Austin, Texas) of the Maastrict School of Management ((Netherlands), ${ }^{1}$ an acknowledged authority and experienced expert on the Technopolis phenomenon in the US and Europe, has postulated that Technopolis regions grow by: 
1. Attracting new companies

2. Nurturing existing indigenous firms

3. Encouraging entrepreneurial start-ups

4. Providing a supportive educational, social, tax, quality-of-life and cultural context for research, technology entrepreneurship and business

5. Networking with other technopoleis worldwide

Dr. Phillips has also listed the following Technopolis Success Factors:

1. Embracing Change

2. Social Capital, especially with cross-sectoral links

3. Cluster strategies that target specific company groups for collaboration

4. Visionary and persistent leadership

5. The will to action

6. Action

7. Constant selling

8. Self-investment in infrastructure

9. Outreach and networking

In Silicon Valley, California and in Boston, Massachusetts, ${ }^{40}$ a combination of top universities (led by Stanford and MIT respectively), local investors, trend-setting cultures, and pioneering technology entrepreneurs have caused those regions to experience the Technopolis phenomenon and take off almost spontaneously.

There are other regions around the world (esp. in the US, Europe and Asia) that are hoping to emulate the successes of these regions with varying degrees of success. In this paper we review the experiences of some of these regions such as Austin (Texas), Ireland, Bangalore (India), Taiwan, and Sophia Antipolis (France) $)^{2,4}$.

\section{Austin, Texas}

The University of Texas at Austin (founded in 1883) was the seminal institution around which the Austin Technopolis took shape. The founding of this university was motivated by Texas pride, the desire to preserve the frontier culture and a perception that wealth would flow from knowledge. Austin's educational infrastructure and entrepreneurial activity existed for decades before the fast, self-sustaining growth occurred. It was Dr. George Kozmetsky who played a key role in the development of Austin as a high-tech mecca. Kozmetzky a founding faculty member of the innovative Graduate School of Industrial Administration at Carnegie Tech (later Carnegie Mellon University) left academia to work for Howard Hughes and later to found the very successful Teledyne Corp. In Austin, he became the city's second god-father of entrepreneurship (after Dean Dr. Frank McBee of the University of Texas Business School), encouraging and investing in many new ventures. Though Dr. George Kozmetzky had preached technology entrepreneurship for decades, it was not until the prices of oil, cattle and real estate - the traditional sources of Texas wealth - all declined precipitously in the 1980s that wealthy Texans decided to heed his sermon and invest in high tech. 
Mukherjee $(2005)^{3}$ shows how the same pattern of government investment, slow infrastructure and entrepreneurial development, followed by a crisis-generated opportunity (the Y2K problem) that spurred the growth of Bangalore (India).

\section{Bangalore (India)}

The recent "buzz" in Bangalore ${ }^{6,7,8}$ is actually just a new chapter in a 100-year history of the south Indian city that began with the founding of the Indian Institute of Science (IISc) by the British colonial rulers and followed through by the socialist government of independent India through a phase of rapid industrialization. One of the most important factors for the success of Bangalore as the pre-eminent region for high tech development in India is the positive, open attitude of its people. Bangalorites have a long tradition of receptivity to ideas. This attitude positions the region for success in the globally linked Innovation Economy. As the capital of the southern state of Karnataka, Bangalore benefits from the early development in infrastructure and strong government support for future growth in facilities. A number of defense and industrial research organizations were established in the city in the 1960s and 1970s. In addition to the IISc, the Indian Institute of Management (IIM) and the National Institute of Advanced Studies (NIAS) are also based in the city. The 25 engineering colleges around the city provide a consistent supply of talent. The literacy rate in Bangalore is relatively high at over $85 \%$ and the state government's IT policy has resulted in fairly strong connectivity in terms of telephone connections and Broadband Internet availability. In 2000, the IT sector was the biggest industry in Bangalore with a base of $32 \%$ of India's software production.

Since 1984, when the Indian government gave Texas Instruments (TI) the right to establish a $100 \%$ self-controlled off-shore center in Bangalore, Multi-National Corporations (MNCs) have been flocking to the region. The conglomeration of large global corporations like TI, Siemens, Phillips, Lucent Technologies, Motorola, Cisco Systems, Ericsson, Sony, Oracle, Sun Microsystems, etc. have been another critical factor in the influx of investment in the region. In the mid 1980s two of India's largest IT companies - Infosys Technologies (started by local engineer-turned-entrepreneur N.R. Narayana Murthy) and Wipro Ltd. (started by US-educated Azim Premji - the scion of a vegetable oil business) established their operations in Bangalore. The International Tech Park of Bangalore located $20 \mathrm{~km}$ outside of the city represents 55\% of the government's investment in the region. It is a joint venture between the Tata Group (one of India's largest corporate houses), a consortium of Singapore companies led by Ascendas Land International Private Ltd. and the Karnataka Industrial Areas Development Board. The aim of this park is to create a "one stop solution" for the high-tech needs of knowledge-based MNCs in India. The park already accommodates major industrial conglomerates in IT-related services like telecommunications, R\&D, financial services, biotechnology, and electronics. Such publicprivate co-operative initiatives have resulted in the explosion of high tech firms in Bangalore from 29 in 1992 to over 800 in 2000 with exports exceeding \$1 Billion. The Indian ethic of dedicated hard work is a societal asset that the managers of large MNCs value greatly. The Bangalore success story can be attributed to the combined support of government leadership in education and industry, and an actively involved world wide diaspora that invests and develops intellectual capital back and forth. There are other regions of India such as Pune and Hyderabad that are emulating Bangalore's successes in the global IT industry. 


\section{Ireland}

The Bangalore success story sounds very similar to that of Ireland. ${ }^{5}$ For the past 150 years, since the advent of the Great Famine, Ireland's major export was its people, who fled the country for their own survival and fro a better future for their children. The continuing emigration threatened Ireland's economic and political independence. This pattern of heavy emigration persisted until the 1970s. Ireland has since transformed itself from a predominantly agricultural society to a high-tech, high-income society with more than 50\% of its GDP in the service sector. Agriculture now makes up a mere 5\% of the GDP and industry comprises 39\%. Since 1994, Ireland has experienced a stunning economic performance, growing at the rate of $9 \%$ to $10 \%$ annually, compared to the European average of $2.5 \%$, making it the fastest -growing economy among the OECD (Organization for Economic Co-operation and Development) countries.

The Irish government has been exemplary in its aggressive economic policies to attract foreign direct investment, which has resulted in the miracle of the Irish economic success. The steps they took were:

1. Abolishment of protectionism in favor of free trade

2. Efforts by the IDA (Investment and Development Agency) Ireland to attract foreign direct investment

3. Provision of capital gains and tax concessions

4. Increased investment in the educational system

5. Successful application for Ireland's membership in the EEC (European Economic Community) in 1973 - which enabled it to reap the benefits of major EEC capital investment in Ireland.

To coordinate the efforts from various agencies and attain its economic goals, the Irish government has set up Forfas as the National Policy and Advisory Board for Enterprise, Trade, Science, Technology and Innovation. Forfas was given broad legal powers for industrial promotion and technology development. It in turn, delegates powers to Enterprise Ireland for the promotion of home-based industry and foreign trade and to IDA Ireland for the promotion of inward investment.

Undoubtedly, the shift in focus from the traditional humanities coursework to technologyoriented curricula in second-level (secondary school education) and in the third level (college and university) education and the close links with the industry since the late 1960s, paved the way for Ireland's competitive advantage. Joining the EU in the 1970s was also a significant step because until then, Ireland was very insular and very protected. The focus on technology also provided leverage in other economic sectors such as financial services, the insurance industry and food processing. In the wake of serious economic downturn in the 1980s - large budget deficit, high taxes, unemployment, and mass emigration - Ireland had developed a system of social partnership among government, employers, unions, and voluntary groups who strived to agree on the priorities for economic and social development. Ireland's young workforce $35.5 \%$ under 25 by year 2010) was also an attractive feature for the MNCs.

The branding and positioning of Ireland as the most favorable region for multi national companies to locate their European operations is one of the great marketing success stories of the 
Innovation Economy. Ireland was positioned as an attractive and profitable place to do business despite significant prejudices and handicaps the country faced in the 1970s and 1980s as an economically and politically troubled region. Just as significant was the determined effort of Ireland to move up the value chain to attract high-tech jobs and operations, not just manufacturing from foreign direct investors. As a result high tech companies such as Intel, EMC, Dell, etc. located their multi-operation functions in Ireland. Ireland has demonstrated that marketing and advertising can work in combination with other factors to create Technopoleis and regional wealth by attracting Multi-National Corporations.

Ireland's efforts very much parallel Taiwan's in moving from a reputation for cheap labor and low taxes to a position of respect as a world class region for the full spectrum of multinational operations.

\section{Taiwan}

Taiwan ${ }^{9,10,11}$ is a great example of a region dedicated to the advancement of the quality of life for its citizens through participation in the Innovation Economy. Taiwan has a very strong hightech market economy. While it lacks land and natural resources, it more than makes up for these inhibiting factors with some terrific strengths in its societal culture: Confucian work ethics, propensity to save, entrepreneurial orientation, and the capacity to engage in risk-taking ventures.

Taiwan has a vast overseas diaspora in the US and it attracts great venture capital streams to its industries, so there ready capital for infrastructure investment and business development. It has a highly educated population and an international perspective, which make it easy for foreigners to work and establish business relationships. It has great supply of high-tech management professionals who have many years of experience in manufacturing.

There is close collaboration between high-tech companies and universities in Taiwan. Universities integrate their curriculum into the high-tech industry needs through the relationships of the schools with the high-tech parks. The science-based knowledge and education of the Taiwanese is a good fit with technology and problem-solving innovation. Taiwan's strong work ethic and its highly skilled, quality-driven workforce is a major competitive advantage. The country has focused step-by-step to develop high-tech industry as a national priority. The tax and incentive system from the government is highly favorable for the kind of capital investment, profit and legal regulations necessary to enable high-tech to thrive. Unlike Singapore or mainland China, the Taiwan government tries to support, but does not try to directly control investment decisions in the high-tech economy.

With its vast overseas diaspora, Taiwan has very good interaction with Silicon Valley and is a good example of a competing region. It has not tried to replicate Silicon Valley, but rather link into it with a great deal of joint research and development, business creation and manufacturing activities.

Taiwan has transformed itself from a low cost manufacturing hub to a high value-added manufacturing center for the world-wide Innovation Economy. It is the pre-eminent region of 
the world for integrated circuit (IC) manufacturing. The Taiwan foundries are manufacturing specialists who are subcontracted by the major semiconductor companies. These foundries such as the \$5 Billion Taiwan Semiconductor Manufacturing Company (TSMC) focus purely on manufacturing, slashing costs through economies of scale. Through aggressive investment, research and development and the advantage of the experience curve in manufacturing, Taiwan has developed chip-making technologies on par with Japan, at a lower cost. Many fabless semiconductor firms world-wide design and sell chips without having to build factories, because they outsource the manufacturing to Taiwan. There is an emerging synergistic engagement between Taiwan and China in the mutual development of manufacturing capabilities. Much of the lower-end manufacturing operations that depend on cheap wages have moved from Taiwan to China.

The Taiwan government intends to position Taiwan as a global center for high value-added manufacturing. The Taiwan Economic Development Advisory Council has identified six areas of support to achieve this objective:

1. Creative research and development

2. Cargo storage and transshipment centers

3. Venture capital investment mechanisms

4. Supply-chain management networks

5. High tech industry capital accumulation systems

6. Value added financial service systems.

Among the jewels in the crown of Taiwan's success are its industrial parks, prominent among them being the Hsinchu Science-based Industrial Park (HSIP), which is an excellent example of public/private and university partnership creating wealth for the region. Since it opened in 1980, the Taiwan government has invested almost $\$ 800$ million in the Parks' infrastructure and administration. HSIP is a great example of a home-grown park with international linkages for companies in the Park as well as international companies into Taiwan. As of 2000, the park had 289 companies in various high tech fields such as IC, computers, telecom, optoelectronics, precision machinery and biotechnology, with over 103,000 employees and total sales of nearly $\$ 30$ billion. Additionally, HSIP is envisioned to be a self-sustaining society with industrial, residential and recreational areas. Besides, the standard plants built by the government and the factories built by the companies, a health clinic, a post office, a customs house, banks, warehouses, and truck depots are all located in the Park.

The Park's integration of universities, research institutes, and diversified high-tech companies makes it the Asian version of Silicon Valley. The government, industry and university partnership in HSIP demonstrates how congruent and focused Taiwan's Technopolis strategy is. Another societal strength derived from the Chinese culture, is an extraordinary cohesiveness and ability to work in formal and informal groups. Taiwanese venture capitalists, engineers, entrepreneurs, and other sectors have many non-government organizations (NGOs) such as SEMI Taiwan, for example, that enable them to work together in Taiwan as well as link internationally to a Chinese high-tech diaspora.

Taiwan seems to always be in the forefront of change and its people are able to create regional wealth whatever happens in the external world. Taiwan is often cited as one of the best examples 
of a developing country that took its economic fate into its own hands by focusing on a unique role in the world economy and leveraging the intelligence, diligence and pluckiness of its people for their common good. In 2000, the Taiwan Miracle has resulted (in a land area one-tenth that of California) in manufacturing $80 \%$ of the world's PC motherboards, $80 \%$ of the world's graphics chips, $70 \%$ of the world's notebooks, $65 \%$ of the world's microchips, $91 \%$ of the world's scanners. Not too bad for an island of 22 million.

\section{Sophia Antipolis - Technology Park the French Way}

In contrast to the fast paced world of high tech markets, France retains the legacy of a "joie de vivre" attitude. However, the country has much to offer in terms of high tech. With 59 million inhabitants and a geographical location at the heart of the European Union (EU), France boasts of the world's fourth largest economy as measured by GDP. Over 8000 non-French firms operate in the country, attracted by its very high quality, high-tech labor force, excellent facilities in R\&D and relatively low wages as compared to neighboring Belgium, Germany and UK.

French engineering schools ${ }^{12}$ are recognized throughout the world for the quality of their graduates, and nearly $40 \%$ of all higher degrees awarded in France are in the fields of engineering and science - the highest percentage in Europe. High-tech intellectual capital in France is created by its 33 higher educational institutions specialized in IT, 25 specialized in electronics, and 19 specialized in telecommunications. The French high-tech companies actively invest for future competitiveness by devoting more than $40 \%$ of total payroll costs to employee training.

France has more than 40 science parks and a wide range of top level research facilities. The French government has traditionally attached a high priority to R \& D. High-tech companies benefit from state-run research through institution such as CNRS (National Center for Scientific Research), INRIA (National Institute for research in Computer Science and Automation), CNET (National Center for Telecommunication studies) and others, which actively collaborate with companies and universities.

Among the science parks in France, Sophia Antipolis 13, 14, 15, 16 exemplifies the French vision toward its participation in the global Innovation Economy. Over the past 30 years, Sophia Antipolis has presented officials with a challenging struggle, and success was not assured. Yet in understanding the role of government in partnership with business, in Sophia Antipolis we can learn from an approach to the commercial development of science, that is very different from the UK and Germany.

In 1960, in a Le Monde article titled "The Latin Quarter in the Fields", French Senator Pierre Lafitte propounded and published a theory that creativity is born through the exchange between industrial, scientific, philosophical and artistic minds. There is an ancient Roman and Greek legacy to integrating knowledge from multiple fields in the arts and sciences. Lafitte believed this mindset was required to enable an inspirational cross-fertilization severely lacking in France and in many European countries. In France he saw an environment in which industry, university and research centers were scattered about randomly and where individuals were increasingly 
taught to become specialists at the expense of having the perspectives of classic all-rounder generalists. It took Lafitte many years to realize his vision of the tri-polarity of research, academia and industry. Today, this vision has taken on the physical form of Sophia Antipolis, the science park in the south of France on the Cote d'Azur.

The first international companies to locate their R\&D centers here were IBM and TI in the early 1960s, taking advantage of the quiet pleasant environment and the abundance of sunshine (which was considered conducive to research and innovation). To capitalize on the international aura and the international accessibility of the region, Pierre Lafitte initiated the Sophia Antipolis Foundation. Toward the end of the 1960s, the Foundation bought 140 hectares of land using private funds. The park was named Sophia Antipolis for Sophia - the Greek word for wisdom and Antipolis for the nearest town of Antibes. Local authorities were invited to join in the 1970s and government help began in 1976.

Originally, only a few companies and institutions settled in the park. Its growth was constant $30 \%$ per year from the beginning. During the 1980s up to 185 companies per year located to Sophia Antipolis. The high-tech park developed its image and its brand, and it started reaching a critical threshold of participants. It was able to draw more and more companies, research centers and educational institutions to the area.

Initially, the different players from industry, research, and education had the habit of working separately, almost in isolation from each other. The Foundation team organized academic, business, engineering and artistic events every week over a period of years, in order to change the sociological and cultural habits.

Today, Sophia Antipolis has an area of 2300 hectares and houses 1300 companies which employ about 40,000 people. The key industries in Sophia Antipolis are IT (esp database and telecommunications), life sciences, materials and energy sciences. There are 110 foreign-owned companies and of the $52 \%$ executive employees, $40 \%$ are foreign-born representing 63 nationalities. Recently, Sophia Antipolis has seen numerous initiatives and projects, which by linking different players and creating synergies from their expertise, have helped lead the way towards more substantial cross-fertilization. Following Lafitte's vision, two-thirds of the park's are was to remain green space, none of the buildings were allowed to be constructed taller than the hills that surround them and no fences or walls were allowed.

Sophia Antipolis demonstrates the importance of a multi-disciplinary approach as a key ingredient of cross-fertilization and entrepreneurship. Creating an entrepreneurship environment from scratch in a conservative, socialist country like France, required many years of development and careful planning.

\section{Critical Success Factors for Technopolis Creation}

We have examined creation of successful Technopolis communities in North America, Europe and Asia. From these observations and experiences, we can conclude that in addition to Dr. Fred Phillips' recently identified nine Technopolis success factors, William Gartner's (Gartner 
1990) ${ }^{44}$ perennial ten ingredients that are pre-requisite for Technopolis creation still hold true: 1) Suitable financing 2) Availability of a competent workforce 3) Accessibility to helpful suppliers 4) Government support or absence of obstacles 5) Proximity of universities to assist in research 6) Availability of land or facilities 7) Access to transportation 8) Support of the local population 9) Available support services 10) Low entry barriers.

Each of the above factors is important. Some of them may be more critical to one Technopolis venture than another, but all of them have a considerable role in ensuring the Technopolis success. Proximity to universities is noteworthy in two respects: In high tech start-ups where new inventions or technologies play a dominant role, these institutions can make significant contribution to successful start-ups through research, problem solutions and engineering support. Another benefit of the university is its business school and the availability of consulting services in terms of marketing, production systems, MIS, accounting and finance advice, etc

Benjamin Mokry (Kirzner 1984) ${ }^{45}$ suggests that in order to create a more receptive environment for high-tech entrepreneurship, a number of fundamental societal changes must occur. He supports the major truism that "local communities are the breeding ground of entrepreneurship" and are capable of creating an environment favorable to it. Mokry has two additional factors to Gartner's list that affect entrepreneurial success:

1) The existence of an entrepreneurial sub-culture. The tremendous success of Silicon Valley, Boston, Austin and San Diego very much support the notion that entrepreneurs feed off each other in a synergistic fashion and create their own dynamic environment, and

2) The availability of incubator organizations, many of which are initiated by local universities and governments as enterprise centers.

Mian and Plosila (1999) ${ }^{46}$ surveyed innovative US technology commercialization mechanisms and discussed the emerging importance of technology commercialization through entrepreneurial support mechanisms and the concerted efforts made by national, state and local governments to promote technology transfer as a way of building regional competitiveness, supporting technological entrepreneurship and recouping economic dividends. Recent studies ${ }^{50}$ have developed a more positive awareness of the value of educating people in entrepreneurship and how to become entrepreneurial. It has been determined that

1) Potential entrepreneurs can be encouraged through university-based entrepreneurship programs

2) Entrepreneurship within an established definition can be taught

3) Entrepreneurial alumni do succeed and they themselves provide further insights and educational materials for dissemination in the classroom.

All the above research work and factors were taken into consideration when we began to develop plans to convert the Space Coast of Central Florida into a hub of high tech entrepreneurial activity.

\section{The Space Coast of Central Florida}

The Space Coast region of East Central Florida has many of the key components necessary for technology innovation, commercialization and entrepreneurship. These elements include the 
NASA Kennedy Space Center, research university systems (Florida Tech, University of Central Florida), an exemplary network of community colleges (Brevard Community College System), high tech companies in electronics and aerospace, and a strong commitment from regional policy makers to transform the local economy heavily rooted in tourism and the space launch programs into a diversified high tech community with a strong entrepreneurial base.

In the past, the many organizations that served the region's economic development efforts for the most part worked in parallel, with limited interaction or synergy. There was also a lack of a comprehensive forum that tied together the processes of technology development, transfer, and commercialization - which is necessary to ignite this type of transformation. Some of the key issues identified on the Space Coast of Central Florida were: 1) Limited availability of entrepreneurship education 2) Very low percentage of commercialization of space and related spin-off technologies 3) Limited infrastructure to support new company formation and incubation

Following the Space Shuttle Challenger and Columbia disasters, and a series of hurricanes, there have been slowdowns in space program activity and layoffs of highly skilled space technicians on the Space Coast. One of the goals of the Space Coast Innovation Outreach Network (SCION) is to retrain and redeploy these skilled resources into careers in high tech entrepreneurship.

Research indicates that teaming researchers and engineers from private industry and universities can help overcome the problem of the "Valley of Death" a dangerous portion of the innovation cycle where technological advances are established, but never put to productive use or brought to market. ${ }^{17}$ The conclusions from the 2002 AUTM Licensing Survey support this by showing that the academic and industrial technology transfer field is an integral part of the innovation economy. However, a key finding was that as federal research funding continued to climb, the industrial funding grew at only one-third the rate, and that research funding linked to licenses and options--a major incentive for academic scientists to participate in the technology transfer process--declined. ${ }^{18}$ The Space Coast Innovation Outreach Network (SCION) Partnership, an informal, synergistic partnership between three colleges of the Florida Institute of Technology (aka FIT or Florida Tech), University of Central Florida (Brevard Campus), Florida Solar Energy Center (FSEC), Technological Research and Development Authority (TRDA) of the State of Florida, FNBIC (Florida NASA Business Incubation Center), SATOP (Space Alliance Technology Outreach Program), Small Business Development Center (SBDC), Economic Development Commission of the Space Coast, NASA Office of Technology Commercialization at $\mathrm{KSC}$, and other local partners, neighboring universities and colleges, plans to dramatically reduce this problem by methodical research and facilitation of best practices for technology transfer and commercialization leveraging a unique educational program in experiential entrepreneurship and technology commercialization.

\section{SCION Objectives:}

The SCION Partnership objectives are to:

1) Develop education and experiential entrepreneurship programs to promote technology commercialization and entrepreneurship awareness 
2) Increase the number of technology entrepreneurs and high tech entrepreneurial start-ups in the Space Coast Region

3) Methodically research the effectiveness and organizational impact of the "Engineering Entrepreneurship" program and workshops on the participants, their organizations, local high tech organizations and the Space Coast area

4) Identify commercial applications of developed and developing space technologies and foster and facilitate technology transfer

5) Provide support activities/events to enable innovation, technology commercialization and entrepreneurial start-ups

6) Provide special program curricula and mentors to underrepresented groups

7) Develop and implement conclusive recommendations to develop sustainable core infrastructure in the areas of education, technology transfer and infrastructure to catalyze and improve the innovation, technology commercialization and entrepreneurial processes

The SCION Partnership is designed after extensive benchmarking with other successful industryacademia technology entrepreneurship and incubation programs such as the entrepreneurship courses and programs at Stanford, MIT, University of Texas-Austin and others. These benchmark universities are a testimony that entrepreneurship skills and know-how can be taught, and that entrepreneurs can be nurtured through support programs in university-based incubators, entrepreneur associations and local business networks. ${ }^{20,21,22,23,24,25,26,27,28,29,39,40,41,42,43,47,48}$ Through NASA's efforts and those of innovative entrepreneurs, thousands of "spin-off' products already have been derived from NASA-developed technology, which collectively, represent an immense contribution to the nation's economy. It is the partnership's intent to recapture the NASA research and development activities in aeronautical and space research for the Space Coast, and to apply these technologies for product development toward improving people's lives. ${ }^{19}$

\section{Education Programming}

Packaging the "incubator concept" into a series of graduate courses, a 3-course Engineering Entrepreneurship certificate program and a series of workshops with activities/events in experiential entrepreneurship, backed by the resources and activities of a technology incubator and methodically studying the impact and outcomes, is a key feature of the SCION Partnership. ${ }^{29}$ The 3-Course Engineering Entrepreneurship Certificate Program consists of the following courses:

1) Engineering Entrepreneurship

2) Technical Marketing / High Tech Product Strategy

3) Technology Commercialization Strategies

A highly successful pilot program in Engineering Entrepreneurship consisting of these three courses was developed and taught by one of the co-authors at KSC in 2002. This widely 
acclaimed prototype program has been featured by the National Collegiate Inventors and Innovators Alliance as a Curricular Model for entrepreneurship education. ${ }^{30,31}$ These courses are continually enhanced for effectiveness using feedback from students, their organizations and the community. Integrating class project teams into extended entrepreneurial "E-Teams" for the commercialization of innovative ideas and utilizing off-the shelf NASA-developed technologies is another strong facet of this partnership. ${ }^{32}$ The SCION Partnership also has plans to develop and deploy a series of intense, innovative 2-day workshops in Technology Commercialization, to generate awareness of the opportunities in this field and create a critical mass of Technology Commercialization Specialists from varied backgrounds (engineers, marketers, lawyers, financiers, investors, retired persons, etc) in the Space Coast area. It is expected that these specialists will source and attract technologies developed outside the area, and make the Space Coast area a hub of high tech entrepreneurial activity.

\section{Application of Program Evaluation Data and Results to Optimize Innovation Pipeline}

The SCION Partnership plans to methodically research the effectiveness and organizational impact of its education programming and other activities on the space coast area and local high tech organizations. In addition to direct feedback into particular program elements, a significant opportunity afforded by the planned analytical research such as this is to apply the results to the overall "innovation pipeline" infrastructure, to yield a more optimized flow, from generating more high quality ideas to an increased conversion rate of these ideas to sustainable commercial and societal activities. In this project, the results of this quite granular research will be evaluated and applied to reduce or remove constraints in the Space Coast region innovation pipeline. The constraints may be removed through curricular optimization, the development of new seminars and boot camp elements, improvement of knowledge delivery mechanisms for certain types of entrepreneurs, and so forth. Though all areas of the pipeline will be considered, several specific opportunities will receive special attention, including:

1. Increased generation and conversion of research and innovation to economic payoff

2. Improved generation and leveraging of available intellectual property

3. Improved industry/university/faculty/student culture for innovation pipeline activities

4. Improved training for innovation pipeline activities

5. More effective bridge-funding mechanisms for the R\&D-to-commercialization gap

6. Improved workforce preparation for commercialization of advanced innovative ideas

\section{Innovation Outcomes}

The performance assessment of the SCION Partnership uses an approach similar to a program review or accreditation process. Objective data and subjective assessments will be collected and tracked by the Florida Tech Office of Institutional Planning, Research and Assessment (OIPRA). A self-study document has been developed using guidelines established by the OIPRA. An external team reviews the self-study document and the program components and administration. In particular, the following steps are followed:

Step 1. Establish a baseline of key indicators

Step 2. Track the key indicators for the duration of the project and thereafter as appropriate

Step 3. Prepare a self-study document

Step 4. Have a visiting team conduct an external review 
To determine the impact of the innovation partnership, it is essential to determine the initial baseline conditions at the outset. Baseline data already collected by The Space Coast EDC and TRDA provides a good starting point and it is planned that this data will be expanded for the baseline study. During the initial years of the partnership, data collected through surveys, extraction and analysis of institutional data, seminar feedback comments, interviews, and focus groups is compiled and analyzed in the following areas:

1. Educational programs (7 metrics)

2. Technology Transfer (11 metrics)

3. Incubation Infrastructure and Support Activities (8 metrics)

4. Overall Program Effectiveness (8 metrics)

It is expected that in creating this initial baseline, required changes to the current information systems are identified and implemented.

\section{Econometric Research Analysis}

The following econometric indices are researched and compiled as a baseline, and tracked annually to determine the impact of SCION Partnership on the Space Coast area - Brevard County, and neighboring Orange County, Volusia County, Osceola County: Cost of Living Index, Average Annual Wages, Adjusted Average Annual Wage, \% High Tech Employment and $\%$ Tourism Employment (based on SIC codes), Geographical Distribution of High-Tech Companies on the Space Coast and Central Florida, Year-to-Year Employment Distribution Comparison on the Space Coast and Central Florida (between High Tech, Other Manufacturing, Tourism-Related, Other Services, Agriculture, Health Care, All Other). A more specific measure of the high tech economic specializations of the Space Coast compared to other high tech regions and the nation with the use of Location Quotients will be developed

\section{Dissemination of Research Results and SCION Achievements and Lessons Learned}

The results of this SCION Partnership activities and achievements are planned to be widely disseminated at local, state, national and international meetings, forums, conferences and publications.

A unique way to disseminate SCION Partnership research results, achievement and lessons learned locally is through Engineering Entrepreneurship Colloquiums organized by the SCION Partnership. In these half-day sessions conducted at the end of every term, and attended by local investors, VCs, inventors, students, faculty, business service providers and interested community members, there will be business plan presentations by the students, a panel discussion on some interesting topic or research finding and a key-note address by a successful inventor. Concurrently, there will be a technology and business service provider fair - and the participants in this fair will typically sponsor the refreshments or pay participation fees which will defray the costs of the event. Forums of this kind have been successfully organized by the authors before with minimal costs and considerable community participation. ${ }^{34,35,36,37}$ 


\section{Initial Impact of the SCION Partnership Activities}

The initial impact of the nascent SCION Partnership activities has been remarkable. The monthly "Engineering Entrepreneur in the Spotlight" double-header seminar series at Florida Tech featuring local innovators and entrepreneurs, their research collaborators and entrepreneur networking / service providers such as TRDA, FNBIC, SATOP, FSEC, Florida Tech Start (Florida Tech's campus-based business accelerator), the Alumni Entrepreneur Alliance and other local organizations have seen increasing attendance and have become an increasingly important networking and discussion forum for local entrepreneurs, inventors, business service providers, investors, students and faculty.

Two NCIIA (National Collegiate Inventors and Innovators Alliance) grants, totaling about $\$ 40 \mathrm{~K}$ for Florida Tech have been central to the rapid increase in entrepreneurial participation by undergraduates and graduate students. One of the grants funded entrepreneurial multi-university wireless senior design projects, while the other supports a series of Electrical and Computer Engineering Department senior design teams with entrepreneurial commitment. This grant requires participating teams to improve their academic entrepreneurial credentials by participating in the series of graduate engineering entrepreneurship courses offered by College of Engineering. The response to these grants has been extremely positive, with 7 of 13 entrepreneurial senior design teams this year intending to launch businesses around their senior projects. Business Plan competitions are held twice a year at Florida Tech and other university/college teams are invited to participate. In 2005, Florida Tech was awarded its first NCIIA E-team grant for developing and commercializing the innovative interactive restaurant guest paging system developed by one of the student senior design teams.

A contagious culture of entrepreneurship and high degree of entrepreneurial awareness has been created on campus. Two Student Entrepreneurs Clubs have been formed on campus affiliated to SIFE (Students in Free Enterprise) and C-E-O (Collegiate Entrepreneur Organization) respectively and these have been very active, with weekly meetings and experiential activities. Some of the community-wide forums organized by Florida TechStart such as the 4-session Intellectual Property workshop, and the alumni entrepreneur panel discussion on "Turning Technology into Value" have seen record attendance from faculty, students and the Space Coast community. The SBIR workshops conducted by the Florida-NASA Business Incubation Center and the Space Coast EDC drew entrepreneurs and inventors from North, South and West Florida to the Space Coast. The NCIIA "Invention to Venture" workshop held at the University of Central Florida in Orlando saw an exponential increase in attendees from the Space Coast. These activities have got considerable publicity from the local media. $49,50,51,52$

\section{Conclusions}

Today's global economy can be characterized by increasing globalization, heightened interdependency and the emergence of a new paradigm of regional, institutional and technological clusters, which facilitate innovation and its commercialization, called the "Technopolis Phenomenon". 
Technopolis communities are sprouting up all over the world and are creating a profound impact on global economic landscapes. We have explored Technopolis Communities in Austin, Ireland, Bangalore, Taiwan, and Sophia-Antipolis, and highlighted their exemplary best practices and summarized their critical success factors. The role of academia-industry-government collaboration in the creation and success of Technopolis communities is discussed in detail. We have concluded that Technopolis community success involves sustained, collaborative efforts by academics, industry representatives, Entrepreneur Support Organizations (ESOs), Economic Development Organizations (EDOs), engineers, entrepreneurs, investors, and other practitioners to develop initiatives, plans, methodologies, infrastructure, and action items.

The authors' experiences in attempting to create a Technopolis Community in on the Space Coast of East Central Florida have been outlined. The initial impact of the nascent SCION Partnership is testimony to the fact that synergistic multi-disciplinary, multi-college, industry/government research partnerships can effectively provide innovative, multi-faceted education programming and networking / support activities to stimulate engineering entrepreneurship and enable technology transfer, thus laying the foundation for a Technopolis community. It is anticipated that these comprehensive Technopolis partnership models can be extended to other universities and geographical regions where technical entrepreneurship and technology transfer have been slow to develop.

\section{References:}

1. Phillips, Fred. "Sustainability of Regional Initiatives for Technology Entrepreneurship". EFMD $35^{\text {th }}$ EISB Conference - Sustaining the Entrepreneurial Spirit over Time - Barcelona (Spain) Sept 12- 14, 2005

2. Saperstein, Jeff and Dr. Daniel Rouach. "Creating Regional Wealth in the Innovation Economy - Models, Perspectives and Best Practices" Financial Times- Prentice Hall, NY, NY 2002.

3. Mukherjee, A. (2005). Can Singapore Become A Fun City? Bloomberg News Service, http://www.bloomberg.com/apps/news?pid+10000039\&sid+aBfOvonc_Yr4\&refer=columnis t_mukherjee

4. Porter, M.E. (1998). "Clusters and the New Economics of Competition" Harvard Business Review: 77-90

5. Central Statistics Office, Ireland. www.eirestat.cso.ie.

6. Bangalorenet. www.bangalorenet.com/internetindia/index.html

7. Digital India: Report on the Indian IT Industry. Centre de Sciences Humaines, 2001

8. Indian IT Industry - Statistics 2001. NASSCOM. www.nasscom.org/it_industry/indic_statistics.asp 
9. Republic of China - Taiwan Government Information Office, www.gio.gov.tw

10. SEMI Taiwan, www.semi.org. January 2002

11. The Industrial Technology Research Institute. www.itri.org.tw.

12. Institute National de la Statistique et des Etudes Economiques Institut. National de la Statistique et des Etudes Economiq (INSEE) www.insee.fr

13. Foundation Sophia Antipolis, www.sophia-antipolis.org

14. CERAM Sophia Antipolis. www.ceram.edu

15. EURECOM Sophia Antipolis. www.eurecom.fr

16. INRIA, www.inria.com

17. Rose Li et. al., "Alignment of Funding Mechanisms with Scientific Opportunities" Regional Forum on Research Business Models - Workshop Summary, Berkeley, CA, (OSTP/NSTC Committee on Science) October 27, 2003

18. Stevens, Ashley: 2002 AUTM (Association of University Technology Managers) Licensing Survey - Dec 2003

19. Sean O'Keefe - NASA Administrator in SPINOFF 2002, Publication of the NASA Office of Aerospace Technology (Commercial Technology Division) - NASA Center for Aero Space Information (CASI) pg 3, 2003

20. Innovation U: New University Roles in a Knowledge Economy - Louis Tornatzky, Paul G Waugaman, Dennis Gray - Southern Growth Policies Board 2002

21. D. Palmintera, J. Bannon, M. Levin aiid A. Pagan (2000) - Developing High Technology Communities: San Diego. Produced under contract to Office of Advocacy, U.S. Small Business Administration, by Innovation Associates, Inc., Reston, Virginia

22. Pacific Partners Consulting Group (1997). An Economic Impact Study of Stanford University. (1995). Stanford. CA. Pacific Partners Consulting Group.

23. C. Jansen and D. Jamison (1999). Technology Transfer and Economic Growth. Salt Lake City, Utah: The University of Utah.

24. Robinson, R. (1998). Technology Transfer. Research Horizons (Summer/Fall) Atlanta: Georgia Institute of Technology 
25. Tornatzky, L., Batts, Y., McCrea, N., Lewis, M. and Quittman, L. (1995). The art and craft of technology business incubation. Research Triangle Park, N.C. Southern Growth Policies Board.

26. Bates, L. (1999). Weighing the pros and cons of attracting new business. Research Horizons (Spring). Atlanta, Ga: Georgia Institute of Technology

27. North Carolina State University. (2001). The New NC State: Becoming the leading land grant institution. Raleigh,N.C.: North Carolina State University

28. Smilor, R., G. Kozmetsky, D.V. Gibson. Creating the Technopolis: Linking Technology Commercialization and Economic Development (1988). Ballinger Publishing Co

29. D'Cruz, Carmo and Tom O'Neal: Turning Engineers Into Entrepreneurs and Transforming A Region. Proceedings of the 2004 American Society for EngineeringEducation (ASEE) Annual Conference. Salt Lake City. UT June 23-25, 2004.

30. NCIIA Website: Curricular Models for Entrepreneurship: http://apps.nciia.net/WebObjects/NciiaResources.woa/wa/View/CurricularModel?n=1000032

31. D'Cruz, Carmo and Tom O'Neal: Integration of Technology Incubator Programs with Academic Entrepreneurship Curriculum -- Technology Management for Re-Shaping the World - PICMET 03 Select Book of 50 Best Papers. Portland OR 2003

32. D'Cruz, Carmo, Ken Ports and Muzaffar Shaikh: Florida Tech Senior Design Commercialization and Entrepreneurship Program - Proceedings of the Portland International Conference on Management of Engineering and Technology (PICMET 2003), Portland, OR July 2003

33. Battelle Memorial Institute Technology Partnership Practice (1998). Technology Partnerships:Benchmarking the Ohio State University and its Peer Institutions. An Action Plan for Positioning the Ohio State University for Leadership. Cleveland, Ohio: Battelle Memorial Institute

34. D'Cruz, Carmo: Strategic Analysis Tools for High Tech Marketing - Proceedings of $23^{\text {rd }}$ ASEM National Conference, Tampa, Oct. 2002

35. D'Cruz, Carmo and Pallavoor Vaidyanathan: "A Holistic Approach to Teaching Engineering Entrepreneurship and Technology Commercialization" - Proceedings of the ASEE National Conference, Nashville, June 2003

36. James W. Carland, F. Hoy, W.R. Boulton, and J.C. Carland, et al., "Differentiating Entrepreneurs from Small Business Owners: A Conceptualization," Academy of Management Review, Vol. 9 (2) 1984, pp 354-359 
37. Clifford G.G. and Shaukry D. Saleh, "A Model of Entrepreneurial Performance," Journal of Small Business Entrepreneurship, 1992 pp 19-26

39. Fred L. Fry, Entrepreneurship: A Planning Approach (NY: West Publishing Co., 1993) p. 40

40. Edward B. Roberts, Entrepreneurs in High Technology: Lessons from MIT and Beyond (New York, Oxford: Oxford University Press, 1991)

41. Henry R. Feeser and Kathleen Watson Dugan, "Entrepreneurial Motivation: A Comparison of High and Low Growth High Tech Founders in Frontiers of Entrepreneurship Research, ed Robert H. Brockhouse, et al.(Wellesley, MA: Babson College, 1989) pp 13-27

42. Allan A. Gibb, "Entrepreneurship, Enterprise and Small Business: State of the Art ?" ed. Bohman and Pousette, Smaforetagsforskning 1 Tiden, $4^{\text {th }}$ Nordic SME Research Conference, Umea Universitet, June 1986

43. John J. Kao, The Entrepreneurial Organization (Englewood Cliffs, N.J.:Prentice Hall, 1991).

44. William B. Gartner, "What Are We Talking About When We Talk About Entrepreneurship ?" Journal of Business Venturing, (5), 1990 pp. 15-28

45. Israel Kirzner, "The Entrepreneurial Process" in The Environment for Entrepreneurship, ed. Calvin A. Kent(Lexington Books, 1984) p. 41

46. Sarfraz Mian, Walter Plosila: University Technology Commercialization Mechanisms: A Survey of Innovative U.S. Programs. Babson College Entrepreneurial Studies. January 1999

47. Russell M. Knight, "Can Business Schools Produce Entrepreneurs ? An Empirical Study," Journal of Small Business and Entrepreneurship, Vol. 5 (1) Summer 1987

48. Virgilio A. Meira Soares and Alberto M.S.C.Amara (1999). "The Entrepreneurial University: a Fine Answer to a Difficult Problem?" Higher Education in Europe, Vol. XXIV, No. 1, 1999.

49. Carmo D'Cruz, Tom O'Neal: $3^{\text {rd }}$ UCF Engineering Entrepreneurship Colloquium at KSC www.techbizfl.com/announ_desc.asp?announceid=61

50. Watt, Chad Eric: UCF whiz kids put biz muscle behind ideas - Orlando Business Journal (Dec 2, 2002) www.bizjournals.com/orlando/stories/2002/12/02/story5.html

51. Heidi Brandow: TRDA Programs Showcased at Florida Tech. (October 2004). http://www.nbia.org/resource_center/in_the_news/member_press_releases/10_04_04_c.html

52. Kelly Lucas: Diverse group Attends Florida Tech's Engineering Entrepreneur in the Spotlight Double Header Seminar (October 2004). http://www.techbizfl.com/announ_desc.asp?announceid=328 